question" is "how useful, or what percentage of patients would be helped by marijuana?"

Others are less convinced. UCSF's Reese Jones, a marijuana researcher who is chairman of the institutional review board that approved Abrams' proposal, says, "It's hard to conceive of it [marijuana] having widespread medical utility. It affects too many bodily systems to make it useful for targeting a specific disease." Jones says that the Abrams study may have some "difficulty getting through a peer-review process because of the way peers look at things", citing particularly the difficulty of accurately calculating the dose of "smoked material". Jones adds, however, that AIDSrelated protocols are often "quite properly often held to a different standard," which may have some effect on peer-review approval.

Regardless of expressed concerns about scientific merit, some researchers and many activists see a conspiracy between the NIDA, DEA and the administration to prevent the potential medical benefits of marijuana from being realized. This belief is denied vigorously by representatives of the different organizations. Although there is a monthly meeting of a committee with representatives from DEA, FDA and NIDA (the Interagency Committee on Drug Control), its purpose is for the agencies to "share relevant information, not to make decisions or form policies," says Millstein.

It is clear, however, that the administration is in an increasingly awkward situation. The incidence of marijuana abuse is rising among adolescents, a phenomenon that largely prompted the July NIDA-sponsored conference to concentrate on methods of prevention and education. Strongly worded speeches condemning marijuana use, delivered by Secretary of Health and Human Services Donna Shalala and Director of the Office of National Drug Control Policy Lee Brown, underlined the Clinton administration's interest in fighting this battle, both to address the problem of abuse, and to silence right-wing critics of its drug policy (and possibly forestall an uncomfortable resurrection of the 'smoked but didn't inhale' gaffe of the last presidential campaign).

The battle over marijuana's medical utility, although showing no sign of ending soon, may ultimately result in some sound, scientific answers. But only if the political battle is decided first.

FinTAN R. STEELE

\title{
Cuts put pinch on UK medical grants
}

Medical researchers in the United Kingdom are reeling from a round of 'damaging and disastrous' cuts in funding. More than 60 first-class research teams are frantically casting around for grants after the Medical Research Council (MRC) announced in July that it will not be able to support their work. The MRC says that, due to a shortage of funds, it has been forced to turn down or defer many top-grade applications, including some of international importance.

The MRC itself admits that the cuts will have severe consequences. Sir David Plaistow, MRC's chairman, said in a written statement, "No one should underestimate the damaging impact which this will have on the growing opportunities for highquality medical research relevant to the health and prosperity of the UK."

Sir Dai Rees, MRC's chief executive, says the Council will not name unsuccessful applicants. "But I can say that there are some vital projects in the area of medical imaging and transplantation, which had considerable investment in them, which we can no longer afford to support."

The MRC says the crisis has arisen because it has not been fully funded to account for inflation and because an increasing proportion of its budget has been earmarked for national projects. These include the human genome project and a new vaccine research institute, as well as grant schemes designed to foster greater collaboration with industry. As a result, the MRC has been left with less money to support ongoing and new research projects.

The full impact of the cuts is unknown, partly because many researchers are not keen to publicize that their grant applications have been turned down. One of the researchers affected who will speak out is Peter Morris, professor of surgery at the University of Oxford. He says that although his programme grant in transplantation immunobiology has been running for 20 years and is well-regarded, the MRC has insufficient funds to support it. "This reflects badly on the whole funding structure of British science, which seems to be in the most parlous state it has been in for years," Morris says. Far from being a burnt-out programme past its prime, referees for his grant application had described it as the "UK flagship in this field."

Ian Young, visiting professor of radiology at the Hammersmith Hospital in London is another casualty of the cuts. He says he hopes to maintain a project involving the application of magnetic resonance imaging to neonatology until he can get proper funding. But the equipment is being supplied by three manufacturers. "If we don't start the work this summer, the equipment will vanish to the US," he says.

This year, only 35 per cent of top-rated applications were funded, compared with 89 per cent in 1993-94 and all of them in 1992-93. In addition, 3 of the 28 very toprated applications were turned down, although an MRC spokesperson says the awards had been deferred by agreement. According to the MRC, this is the first time in recent years that it has been unable to fund all, or virtually all, long-term research proposals in these high-quality categories.

The news about the grants became public at the end of July, after the MRC approved an allocation of $£, 35$ million (US\$55 million) for long-term support of new research programmes. This was the final slice of research funding to be allocated in the current award year and brought the year's total allocation for such research projects, some of which run for three to five years, to $£ 76$ million ( $\$ 120$ million).

But the MRC says it had available $£ 5$ million a year less in 1994-95 than it did in 1993-94, which, it claims, was itself a difficult year. This translates into a shortfall of about $£ 20$ million over the period for which the awards were made.

SHARON KINGMAN London

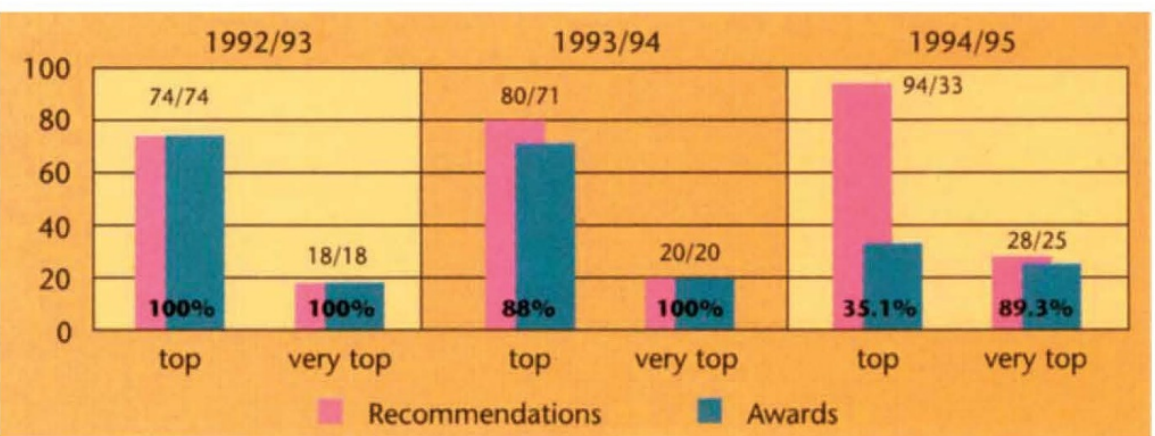

